\title{
AS FARPAS DA HISTÓRIA: LAMPEJOS NA POESIA DE GiovaNNI RABONI
}

\author{
Le Schegge della Storia: Barlumi nella Poesia di \\ Giovanni Raboni
}

\author{
The Splinters of History: Glimmers in Giovanni \\ Raboni's Poetry
}

ELENa SANTI*

RESUMO: A coletânea Barlumi di storia de Giovanni Raboni aparece intimamente ligada, desde o título, com a história privada e coletiva. Porém, é uma história que não se apresenta como imediatamente legível, tudo é visto em filigrana, por lampejos, em uma perspectiva benjaminiana. Os espaços são interrogados e, na contraluz da existência, aparecem as farpas dos fatos históricos que penetram na carne do poema, transfigurados por meio da palavra poética. Esse procedimento resulta evidente desde o começo de sua trajetória, não somente poética, mas no campo da editoria e de sua atuação em duas importantes revistas: aut aut e Questo e altro. O objetivo deste trabalho é traçar esse percurso na poesia de Raboni, pondo em diálogo essas experiências editoriais com a última coletânea indicada. No específico, será analisado o poema "Ogni tanto oétic", em que o olhar do poeta atravessa a piazza Fontana, tristemente famosa por ter sido o palco do atentado à Banca Nazionale dell'Agricoltura (12 de dezembro de 1969), evento que inaugura a época do terrorismo na Itália. É por meio da descrição da praça que o poeta pode falar sobre o acontecimento histórico, que ecoa em todo o poema, sem ser propriamente nomeado. A história aparece na sombra, no ausente, nas dobras da experiência. Para desdobrar essa relação entre história, memória e palavra poética em Raboni, tentaremos um diálogo pontual com o poeta Gianni D'Elia, com quem compartilha uma visão de poesia que não pode se abster do seu papel social e político.

PALAVRAS-CHAVE: História; Memória; Esquecimento.

RIASSUNTO: La raccolta Barlumi di storia del poeta Giovanni Raboni si mostra intimamente legata, fin dal titolo, alla storia privata e collettiva. Tuttavia, è una storia che

* Universidade Federal de Juiz de Fora (UFJF)
es.elenasanti@gmail.com - (ORCID: 0000-0002-6734-6896)
DOI: http://dx.doi.org/10.11606/issn.2238-8281.v0i41p35-47 
non si presenta come immediatamente leggibile, tutto è visto in filigrana, per barlumi, in una prospettiva benjaminiana. Gli spazi sono interrogati e, in controluce all'esistenza, appaiono le schegge dei fatti storici che penetrano nella carne della poesia, trasfigurati attraverso la parola poetica. Questo procedimento risulta evidente fin dall'inizio della sua traiettoria, non soltanto poetica, ma anche nel campo dell'editoria e della sua collaborazione con due importanti riviste aut aut e Questo e altro. L'obiettivo di questo lavoro è tracciare un percorso nella poesia di Raboni, facendo dialogare queste esperienze editoriali con la raccolta citata. Nello specifico, sarà analizzata la poesia "Ogni tanto succede", in cui lo sguardo del poeta attraversa piazza Fontana, tristemente famosa per essere stata palcoscenico dell'attentato alla Banca Nazionale dell'Agricoltura (12 dicembre 1969), evento che inaugura l'epoca del terrorismo in Italia. È attraverso della descrizione della piazza che il poeta può parlare del fatto storico, che echeggia in tutta la poesia, senza essere propriamente nominato. La storia appare nell'ombra, nell'assente, nelle pieghe dell'esperienza. Per sviluppare questa relazione fra storia, memoria e parola poetica in Raboni, tenteremo un dialogo puntuale con il poeta Gianni D'Elia, con cui condivide una visione di poesia che non si può astenere dal suo ruolo sociale $\mathrm{e}$ politico.

PAROLE-CHIAVE: Storia; Memoria; Oblio.

ABSTRACT: The collection Barlumi di storia by Giovanni Raboni appears linked, since the title, with a private and collective history. However, it is a story that does not present itself as immediately readable, everything is seen in filigree, by flashes, in a Benjaminian perspective. The spaces are questioned and, in the light of existence, the splinters of historical facts penetrate the flesh of the poem, transfigured through the poetic word. This procedure has been evident since the beginning of its trajectory, also in the field of publishing and its performance in two important magazines oética and Questo e altro. The objective of this work is to trace a path in Raboni's poetry, putting these editorial experiences in dialogue with the indicated collection. Specifically, the poem "Ogni Tanto Succede" will be analyzed, in which the poet's gaze crosses piazza Fontana, famous for being the stage of the attack on the Banca Nazionale dell'Agricoltura (December 12, 1969), an event that commence a time of terrorism in Italy. It is through the description of the square that the poet can talk about the historical event, which echoes throughout the poem, without it being properly named. History appears in the shadow, in the absent, in the folds of experience. In order to investigate this relationship between history, memory and the poetic word in Raboni, we will seek for a specific dialogue with the poet Gianni D'Elia, with whom he shares a vision of poetry that cannot abstain itself from its social and political role.

KEYWORDS: History; Memory; Forgetfulness. 


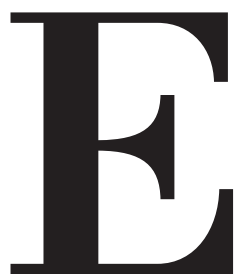

m momentos diferentes de sua vasta produção poética e crítica, Giovanni Raboni (1932-2004) expressa sua concepção de história que, do seu ponto de vista, é o grande elemento unificante das experiências e manifestações humanas. Em outras palavras, nada é possível fora dela, não há acontecimento a não ser, justamente, dentro da história. Essas reflexões, que colocam o elemento histórico em uma posição de destaque no que diz respeito à experiência humana, apontam para os escritos benjaminianos sobre o anjo da história. Por meio da imagem do Angelus Novus de Paul Klee, Walter Benjamin descreve a imagem do anjo da história, cujos "olhos estão escancarados, sua boca dilatada, suas asas abertas" (BENJAMIN, 1994, p. 226). O anjo dirige o olhar para o passado, enquanto uma tempestade o obriga a manter as asas abertas, empurrando-o para o futuro. Apesar da força do progresso, que o obriga a ir para frente, o anjo não desvia o olhar do passado, cujas marcas estão impressas no presente. A história, portanto, para Raboni, se configura como essa contínua troca entre presente e passado, cujos rastros são legíveis no hoje, assim como nos corpos dos vivos há os rastros dos próprios mortos. Como expressado de forma explícita, a partir do título, na coletânea Barlumi di storia (2002), a história não é um fluir pacífico de eventos, perfeitamente interligados, que cronologicamente deixam lugar uns aos outros, mas é feita de lampejos, de luzes súbitas, que iluminam fragmentos do passado, criando uma imagem - a imagem dialética de Benjamin - que "perpassa veloz. O passado só se deixa fixar, como imagem que relampeja irreversivelmente, no momento em que é reconhecido" (BENJAMIN, 1994, p. 224). O passado, então, consegue se fazer presente, por instantes de iluminação, para depois se esvanecer no esquecimento.

Essa relação com o tempo, com a história, com o passado, tem também um valor ético. Não esterilizar o passado fechando-o em classificações inertes, significa deixar aberta a possibilidade de agir no presente, mostrar seu rosto, não perder de vista aquilo que, mesmo que perdido, possa ainda nos devolver sua imagem, em um relâmpago. Podemos pensar nas lascas que Georges Didi-Huberman arranca das bétulas em Birkenau, e na montagem que faz a partir delas, em Cascas (2013). Aquele passado, o do lager nazista, anestetizado, encaixado na rígida visita turística pré-estabelecida, volta à vida e dá frutos, naquela dobra temporal criada pelas montagens que o crítico faz na folha em branco: 
Vemos aqui três lascas arrancadas de uma árvore, há algumas semanas, na Polônia. Três lascas de tempo. Meu próprio tempo em lascas: um pedaço de memória, essa coisa não escrita que tento ler; um pedaço de presente, aqui, sob meus olhos, sobre a branca página; um pedaço de desejo, a carta a ser escrita, mas para quem? (DIDIHUBERMAN, 2013, p. 100)

O passado pode agir, iluminar o presente, por meio de seus lampejos, que nos mostram suas marcas no tempo presente. Não é possível ver o passado como algo fechado e distante, objeto de uma narração orgânica e fixada, sempre igual a ela mesma. E aqui se desdobra a perspectiva ética de Raboni: permitir esse movimento, se colocando numa posição de atenção e escuta do tempo, da história, dos objetos que nela se intersectam. Literatura, política, sociedade não podem se encontrar senão nessa intersecção. Por isso, na opinião de Raboni, o engajamento da literatura é, na realidade, um problema falso. O objetivo não é a verdade, conceito vazio se aplicado aos fatos humanos. Se fora da história nada é possível, a palavra, por sua vez, pode ter lugar somente na história. Falar na história, como nos diz Raboni, não significa tomar a palavra para defender uma suposta verdade em detrimento de outras, mas, pelo contrário, significa assumir essa dimensão da história que, mesmo sendo o cenário comum a tudo, permanece um conceito plural, composto pelos acontecimentos e do qual podem ser feitas diferentes leituras. As palavras, por sua vez, trazem consigo uma carga, uma sedimentação semântica que lhes é dada pelo uso, pelas vivências humanas, pelo fato de serem vivas na história. O poeta não pode desconhecer essa carga, anulá-la, ou torná-la inofensiva, pelo contrário, deve conhecê-la e compreendê-la, porque uma palavra que é pronunciada fora da história perde suas possibilidades criativas. O papel do escritor é, então, o de escrever na história, isto é, de não fugir do contato com esse contexto complexo e ambíguo no seu ser totalizante e, assim, não pronunciar palavras vazias:

O engajamento do escritor - ou, em outras palavras, sua capacidade, seu poder de contestação e dissenso - não se encontra, evidentemente, na expressão desta ou daquela determinada crítica, no denunciar esta ou aquela violência específica, mas na tomada de palavra "dentro da história", no falar sem evadir a história. E, neste ponto, é claro, juízo estético e juízo de pertencimento não podem senão coincidir. O escritor que evade a história, que fala sem dizer, que aceita mover os lábios "imitando" a tomada de palavra no fragoroso silêncio da mentira consumística, é um escritor que diz o falso, um não-escritor. Escritor é somente quem fala dentro da história, assim como só o homem que vive está vivo.1 (RABONI apud CHELLA, 2016, p. 346)

Quem quer omitir o próprio discurso da história renuncia ao ato de tomar a palavra, simplesmente o imita, transformando-o em uma casca sem vida nem substância. Para ser vivo é necessário viver, para ser escritor é necessário tomar a palavra na história. Isso significa que é necessário estar consciente do próprio espaço de enunciação, de onde se fala, a partir de

1 "L'impegno dello scrittore - o, in altri termini, la sua capacità, il suo potere di contestazione e di dissenso - non sta, evidentemente, nell'esprimere questa o quella determinata critica, nel denunciare questa o quella violenza specifica, ma nella presa di parola 'dentro la storia', nel parlare senza evadere dalla storia. E su questo punto, è chiaro, giudizio estetico e giudizio di appartenenza non possono che coincidere. Lo scrittore che evade dalla storia, che parla senza dire, che accetta di muovere le labbra 'mimando' la presa di parola nel fragoroso silenzio della menzogna consumistica, è uno scrittore che dice il falso, un non-scrittore. Scrittore è solo chi parla dentro la storia, così come solo l'uomo che vive è vivo" (todas as traduções foram realizadas pela autora do texto, salvo quando houver indicações específicas). 
quais pressupostos, sem esquecer que é no interior da história que é necessário se inscrever, ou seja, tendo presentes as tensões e as relações que são subentendidas. Ser poeta político, então, significa não renunciar a essa tomada de palavra. Como poeta, "ele não pode não notar como a responsabilidade de quem escreve acontece, mais do que no plano dos conteúdos e da crítica, [...] no terreno, mais especificamente literário, da própria palavra"2 (CHELLA, 2016, p. 347). Portanto, não é o tema que define certa função política da obra, ou certo grau ético, mas, é uma questão intimamente ligada à palavra, se for pronunciada considerando os fatos humanos que nela estão contidos, se houver história, se houver vida, ou se, pelo contrário, tiver sido neutralizada, se tiver sido transformada em um falar sem dizer.

A relação que Raboni entretém com a história resulta evidente desde sua atividade com duas revistas que foram fundamentais para sua formação cultural: aut aut e Questo e altro, que se tornaram importantes espaços de debate cultural. Ambas são ligadas à figura do editor Arrigo Lampugnani Nigri, seu amigo desde a época da escola. Os dois se retiraram do liceo oética para poder preparar a maturità autonomamente, e Lampugnani Nigri, cuja família tinha maiores possibilidades econômicas, tinha à disposição professores particulares intelectuais e poetas como Enzo Paci e Vittorio Sereni. Dessa amizade nasceu, sucessivamente, uma editora que, não somente publicou duas obras poéticas de Raboni, mas também as citadas revistas. Em uma intervenção, ao comentar sua relação com Raboni, Lampugnani Nigri escreve:

Giovanni se inseriu rapidamente e de fato tornou-se o diretor geral do grupo, se dedicando muito indiretamente também na aut aut, a revista que havia tempo eu publicava para Enzo Paci.

Após alguns anos, construímos uma pequena editora nossa (50\% para cada, Rab era o presidente). Paci acompanhava a parte de ensaística e filosofia, com os redatores da aut aut, Veca e Rovatti. Para a poesia, Rab "a tempo perdido". Em 1961, após ter muito insistido para convencer Giovanni, publiquei o primeiro pequeno volume de seus poemas, Il catalogo è questo. Em 1967, publiquei um segundo, Gesta Romanorum. Depois, pensamos em publicar uma revista de literatura; envolvemos Vittorio Sereni e nasceu Questo e altro (primeiro número em 1962). Os diretores eram Niccolò Gallo, Dante Isella, Geno Pampaloni, Vittorio Sereni, secretário de redação Carlo Della Corte, distribuído pela Mondadori. Raboni não aparecia oficialmente porque, mesmo sendo, poderíamos dizer, a alma da revista, participava comigo como editor. ${ }^{3}$ (LAMPUGNANI NIGRI, 2014, p. 20-21)

2 "egli non può non notare come la responsabilità di chi scrive si giochi, più che sul piano dei contenuti e della critica, $[\ldots]$ sul terreno, più specificamente letterario, della parola stessa".

3 Giovanni si inserisce rapidamente e di fatto diventa il direttore generale del gruppo, occupandosi molto indirettamente anche di «aut aut», la rivista che da tempo pubblicavo per Enzo Paci.

Dopo qualche anno abbiamo costruito una nostra piccola casa editrice (al $50 \%$ Rab ed io, Rab era il presidente). Paci seguiva la parte di saggistica e filosofia, con i redattori di «aut aut» Veca e Rovatti. Per la poesia Rab "a tempo perso". Nel 1961, dopo aver molto insistito per convincere Giovanni, pubblico il primo volumetto di sue poesie Il catalogo è questo. Nel 1967 ne pubblicherò un secondo Gesta Romanorum. Poi ci venne in mente di pubblicare una rivista di letteratura; coinvolgiamo Vittorio Sereni e nasce «Questo e altro» (primo numero nel 1962). I direttori sono Niccolò Gallo, Dante Isella, Geno Pampaloni, Vittorio Sereni, segretario di redazione Carlo Della Corte, distribuito da Mondadori. Raboni non appare ufficialmente perché, pur essendo, potremmo dire, l'anima della rivista, partecipava con me come Editore.". 
Enquanto aut aut ${ }^{4}$, fundada em 1951, se ocupa principalmente de filosofia, ligada à figura importante de Enzo Paci, Questo e altro se inscreve diretamente no horizonte literário. Fundada em Milão em 1962, investiga com interesse a relação que existe entre o mundo literário e a realidade, uma espécie de instrumento de reflexão para dialogar justamente com o outro, aquilo que não é estritamente literário, mas que com a literatura tem relação. O objetivo não era o de buscar correspondências, mas o de procurar hibridações e formas de diálogo que nascem, inicialmente, da proximidade. "Isto e outro", elementos que, mesmo conservando uma própria autonomia, se tocam e contaminam, criando possibilidades expressivas, novas formas de enunciação:

[...] porque discutindo de literatura - e não somente de literatura como tal, mas, também, como no título da revista, de suas relações com o "outro" - se acaba pouco a pouco com o encontrar-se imergidos em um fervor um pouco especial, uma espera de respostas (e de sentido) que beira, não digo a previdência, mas também, com certeza, a inquietação. ${ }^{5}$ (RABONI, 2006, p. 1245)

Os anos em que a revista vê a luz são muito ricos de acontecimentos, de sugestões e de inquietações. Como afirma Raboni em uma prosa que se encontra sempre em Barlumi di storia, a década de sessenta foi saudada pelos intelectuais como um período em que, após os duros anos do imediato pós-guerra e os anos cinquenta, poderia haver um "inebriante degelo"6 (RABONI, 2006, p. 1247), era possível voltar a discutir, sentender-se, encontrar-se, deixando de lado as posições pré-constituídas, derrubando as barricadas. A revista nasceu da ideia que a "literatura fosse reconhecida e defendida não somente na sua especificidade e autonomia, mas, também, como 'uma forma de conhecimento do mundo' e 'um lugar da verdade humana" (RABONI, 2006, p. 1247), isto é, que, por meio da literatura, e tratando de literatura em sua especificidade, fosse possível conhecer o mundo e o homem, poder falar de tudo, dar a própria contribuição para as discussões que estavam sendo desenvolvidas na Itália e em outros lugares. Contudo, Raboni e o grupo entorno da revista, tiveram que enfrentar a realidade histórica, já que algumas de suas esperanças, em pouco tempo, foram frustradas. Em uma entrevista que Massimo Gezzi realizou com Raboni para a revista Atelier $^{8}$, Raboni identifica o ano de 1963 como o momento em que, ainda de maneira não completamente consciente, se infringem as certezas desse grupo de intelectuais: o assassinato de Kennedy, a morte do papa João XXIII, junto com os acontecimentos de anos anteriores, em Budapeste, em 1956, quando o exército soviético invadiu a capital da Hungria sufocando a revolução. As figuras que estavam transmitindo aquele sentimento de abertura, que animava a vida cultural da época, se foram todas no mesmo ano, deixando as promessas de mudanças não cumpridas:

4 A revista está disponível no site: http://autaut.ilsaggiatore.com/. Acesso em 17 ago. 2020.

5 "perché discutendo di letteratura - e non solo di letteratura in quanto tale ma anche, giusto il titolo della rivista, dei suoi rapporti con l'«altro» - si finisce a poco a poco col trovarsi immersi in un fervore un po' speciale, un'attesa di risposte (e di senso) che rasenta non dico la preveggenza, ma anche certamente l'inquietudine.".

6 "Inebriante disgelo".

7 "letteratura venisse riconosciuta e difesa non soltanto nella sua specificità e autonomia, ma anche come «una forma di conoscenza del mondo» e «un luogo della verità umana»".

8 Atelier, n. 29, marzo 2003. Disponível em: http://www.andreatemporelli.com/wp-content/uploads/2015/08/ Atelier-29-VIII-marzo-2003.pdf, p. 29-40. Acesso em 24 ago. 2020. 
Isto não elimina o fato que os tiros de fuzil de Dallas ressoaram em nós, naquela noite de novembro, como um brusco, terrível rasgo para trás. E foi também - assim, pelo menos, penso agora - como se os tiros acertassem de raspão e, contudo, mortalmente, a nossa esperança ou utopia de poder frequentar publicamente e coletivamente a literatura como um "isto" a ser emparelhado com um "outro", como "um lugar da verdade humana". 9 (RABONI, 2006, p. 1248)

O ano de 1963, então, representa o ápice e o fim daquilo que Raboni chama de utopia: a esperança de encontrar um lugar da verdade humana, de poder fazer da palavra e da poesia uma casa para a verdade do homem e da história. Se Questo e altro não sobreviveu ao embate violento com a história e os eventos, é importante lembrar que aut aut continua sendo publicada, tecendo ligações entre filosofia, história, política e psicanálise, abraçando uma visão da cultura complexa e compósita.

A experiência das revistas é também importante como registro de uma série de reflexões que acompanhavam Raboni nesse período. Em um artigo de 1962, que foi publicado em Questo $e$ altro, ele enumera alguns dos elementos fundamentais, no seu entendimento, da poesia de Clemente Rebora: suas palavras tem um "peso", uma grossura, certa força, já que dentro delas a história não se perde, mas, ao contrário, mantêm grumos de realidade, uma ligação com o uso quotidiano, sem serem completamente transfiguradas poeticamente. Essa posição de Raboni no começo de sua carreira, mesmo passando por transformações até profundas, continua influenciando sua poesia até, como já afirmado, às últimas coletâneas:

Está claro que o problema da relação entre a escrita e as vicissitudes humanas foi enfrentado por Raboni não muito, e não somente, em termos ideológicos e morais, mas, antes de mais nada, no plano da palavra, em sua materialidade na própria página poética. O dilema, em suma, não tem a ver simplesmente com qual conteúdo abordar, qual história contar, mas é de natureza propriamente técnica e estilística: como tornar a palavra poética capaz de absorver e devolver as contradições do quotidiano e do passado? Por meio de quais instrumentos, metáforas, escolhas linguísticas, modelos, transportar na página o tempo e o ritmo dos eventos humanos? Essas interrogações atravessam, de livro em livro, de coletânea em coletânea, todo o percurso poético de Raboni, em que a história, passada e presente, aflora na página de maneiras diferentes: através de estratagemas, metáforas, filtros compositivos; por detalhes e lampejos da memória; passando através do buraco de agulha das vicissitudes íntimas e pessoais de quem escreve, já que a história individual acaba por espelhar-se constantemente na história da comunidade humana, feita de vivos mas também de mortos, da qual o poeta se sente parte. ${ }^{10}$ (CHELLA, 2016, p. 348)

9 "Ciò non toglie che i colpi di fucile di Dallas risuonarono per noi, in quella sera di novembre, come un brusco, terribile strappo all'indietro. E fu anche - così, almeno, mi viene da pensare ora - come se essi colpissero di striscio e tuttavia mortalmente la nostra speranza o utopia di poter frequentare pubblicamente e collettivamente la letteratura come un «questo» da abbinare a un «altro», come «un luogo della verità umana»".

$10 \quad$ "È chiaro che il problema del rapporto tra la scrittura e le vicende umane venga affrontato da Raboni non tanto e non solo in termini ideologici e morali, ma prima di tutto sul piano della parola, sulla materialità della pagina poetica stessa. Il dilemma, insomma, non riguarda semplicemente quale contenuto affrontare, quale storia raccontare, ma è di natura propriamente tecnica e stilistica: come rendere la parola poetica capace di assorbire e restituire le contraddizioni del quotidiano e del passato? Attraverso quali strumenti, metafore, scelte linguistiche, modelli trasportare sulla pagina il tempo e il ritmo degli eventi umani? Questi interrogativi attraversano, di libro in libro, di raccolta in raccolta, tutto il percorso poetico di Raboni, in cui la storia, passata e presente, affiora sulla pagina in modi diversi: 
As coletâneas que têm a sua gestação nesse período de grande reflexão sobre as ligações entre história e palavra não podem deixar de perceber o fenômeno profundamente, seja de maneira explícita e evidente, como a referência a fatos da atualidade entre os versos, seja por meio do uso de imagens do passado para falar do presente, ou, novamente, a interposição de figuras e personagens para falar de si mesmo, da própria visão das coisas. A história, de fato, segundo Raboni, não é representável diretamente, não há uma correspondência direta entre os eventos humanos e a página poética. É representada, pelo contrário, como se fosse atingida por uma luz oblíqua, "di taglio" (RABONI, 2006, p. 1756).

Essa representação oblíqua da história utiliza diversos elementos, filtros, instrumentos de refração, que têm a função de transfigurar poeticamente o fato histórico. Como precedentemente afirmado, sua concepção de fluir histórico não é cronológica, mas, feita de lacunas, de cortes, sobressaltos temporais, de lampejos. O tempo, então, tem um andamento descontínuo, feito de acelerações e desacelerações, estremecimentos do passado e da memória, que, portanto, não admitem uma narração histórica simples e linear, mas que saiba acolher estas complexidade e sobreposição de tempos. O discurso que aspire falar de história e de tempo deve necessariamente aceitar esta sua dimensão, esta ancoragem "no inconsciente e sua dimensão anacrônica" (DIDI-HUBERMAN, 2015, p. 41). Um tempo que é algo muito mais interior que exterior, mediado pelo sujeito, e que mostra o passado não como foi, mas como é lembrado. É uma memória frágil aquela que Raboni coloca em cena, uma memória que, com frequência, entra em choque com o quotidiano, misturando elementos vividos e outros lembrados. Nesse sentido, diversos elementos provocam o reaflorar do passado através da memória, provocando um cruzamento de tempos heterogêneos que é entranhado na experiência da história e do tempo. Objetos, sensações, vozes e imagens que permitem as estratificações de tempos que são operadas pela memória. Uma memória que, contudo, se apresenta lacunosa e incerta, já que, no seu ser fragmentada, pode ser operada e presentificada involuntariamente:

Para se chegar aos múltiplos tempos estratificados, à sobrevivências, às longas durações do mais-que-passado mnésico, é preciso o mais-que-presente de um ato reminiscente: um choque, um rasgar do véu, uma irrupção ou aparição do tempo, tudo o que Proust e Benjamin disseram tão bem sobre a "memória involuntária". (DIDI-

HUBERMAN, 2015, p. 26)

O anacronismo, suspendendo o fluxo temporal, provoca um curto-circuito entre passado e presente, que lança uma nova luz sobre o fato histórico que se quer retratar, desloca o ponto de vista, traz, em certa medida, o fato temporal. No laboratório poético raboniano, um exemplo importante é representado pelo Lazzaretto ${ }^{11}$, que dá corpo a um nó temporal, em que a anula-

tramite stratagemmi, metafore, filtri compositivi; per dettagli e per barlumi della memoria; passando attraverso la cruna delle vicende intime e personali di chi scrive, poiché la storia individuale finisce per specchiarsi costantemente nella storia della comunità umana, fatta di vivi ma anche di morti, di cui il poeta si sente parte.".

11 A referência aqui é ao Lazzaretto de Milão, perto de Porta Venezia, construído entre o século XV e XVI. Nesse lugar eram isolados os acometidos pela peste e é retratado também no romance Os noivos de Alessandro Manzoni. 
ção do fluxo não representa um apagamento da história, mas, pelo contrário, a potencializa. O Lazzaretto, de fato, não anula, com sua carga histórica, o presente, pelo contrário, seu presente e seu passado se fundem e confundem, se releem reciprocamente. Outro momento em que a reflexão sobre o tempo se explicita é dado pelo uso do tema bíblico que, novamente, permite ao poeta falar de outras coisas, do presente, mas sempre relido por meio da luz oblíqua que é projetada pelo passado, transportando na página poética uma história que, no fundo, é uma suspensão do tempo cronológico em si, tornando-se uma releitura. Ademais, é importante destacar como, de certo ponto de vista, a orientação religiosa de Raboni e seu engajamento político, são, de certa maneira, coincidentes em alguns aspectos. Isso não significa que a religiosidade de Raboni seja política, mas, pelo contrário, que tanto sua visão política da história e da sociedade, quanto sua inspiração religiosa, se baseiam nas mesmas fundações éticas: "Raboni é um dos pouquíssimos poetas dignos deste nome que podem se dizer naturaliter poetas engajados" 12 (ZANZOTTO, 2006, p. XI), não por uma tomada de posição programática, mas porque tudo recai "no campo de uma ética da responsabilidade e da cidadania"13 (p. XI). É nesse terreno, nessa ideia de comunidade que é constante em Raboni que "a força de uma tradição cristã e a de uma ideologia marxiana se entrecruzam"14 (p. XI). Do ponto de vista de Andrea Zanzotto, emerge, então, um retrato de uma vocação civil que é enraizada na sua maneira de ver e pensar a realidade e a poesia, e que não pode ser evitada. Uma atitude, por alguns aspectos complementar, embora antitética por outros, é a do poeta Gianni D'Elia, que pertence a uma geração sucessiva à de Raboni. O poeta de Pesaro compartilha com Raboni um olhar profundamente crítico sobre a realidade e a atualidade, assumindo, contudo, posições abertamente engajadas, não mais em filigrana, ou como consequência de algo que toca profundamente o poeta, mas é o foco do próprio fazer poético. Interlocutores como Pier Paolo Pasolini, Giovanni Giudici, Franco Fortini (nomes - principalmente os últimos dois - importantíssimos também para Raboni), são fundamentais para compreender sua inspiração militante, mas, também, profundamente atentos à musicalidade do verso e ao diálogo com a prosa ${ }^{15}$. A tradução de Baudelaire é outro elemento que aproxima Fortini de Raboni, já que sua última coletânea é intitulada Fiori del mare (2015). Para o volume Vozes: cinco décadas de poesia italiana (2017), D'Elia cedeu um texto até então inédito, cujo título é: "Para o Aniversário da Bela Morta" (p. 219). Retomando estruturas estróficas mais ou menos tradicionais, o poeta repensa alguns momentos nevrálgicos da história italiana, assumindo uma posição de condenação da cobiça e covardia que desvalorizaram a dignidade do país: "Riqueza, Independência, Partilha, / por cobiça e estrangeiros venenos, / pois é assim que o Sol não mais brilha / pelas trevas em que reviveremos" (D'ELIA apud PETERLE; SANTI, 2017, p. 219). É interessante notar que, embora o tom engajado seja claramente percebível, D'Elia publica esse poema juntamente com um comentário autoral, em que nomeia claramente as referências à história recente que no texto tinham permanecido subentendidos: o delito Mattei, a morte de Pasolini, o assassinato de Aldo Moro,

12 "Raboni è uno dei pochissimi poeti degni di questo nome che si possono dire naturaliter poeti civili".

13 "nel campo di un'etica della responsabilità e del civismo".

14 "la forza di una tradizione cristiana e quella dell'ideologia marxiana si intrecciano".

15 Para aprofundar o discurso sobre a poesia de Gianni D'Elia, indicamos a introdução à sua entrevista no livro: PETERLE, Patricia; SANTI, Elena. Vozes: cinco décadas de poesia italiana. Rio de Janeiro: Comunità, 2017, p. 211-213. 
formando uma trilogia trágica que marcou, inevitavelmente, o declínio da Itália: "Sem esses três lumes claros da economia, da cultura e da política, a Itália não foi mais a mesma e iniciou seu declínio" (2017, p. 219). Em outras palavras, podemos entrever aqui um gesto que, de certo modo, vai em direção oposta àquela de Raboni. Para o poeta de Milão o engajamento é quase uma consequência inevitável, uma reação aos eventos do mundo que, tocando em profundidade o poeta, o obrigam a falar. $\mathrm{O}$ fato histórico, contudo, passa por uma transfiguração poética que entrega ao não dito, mais do que ao evidente, a função política. Podemos pensar em um texto publicado por Raboni em Barlumi di storia. Aqui o poeta nomeia um lugar emblemático da história da segunda metade do século XX:

Por vezes acontece

de atravessar a Piazza Fontana.

Como muitas praças de Milão,

também a Piazza Fontana

com suas quatro plantas doídas

e seu perímetro fugidio

como se já nenhuma geometria

fosse não digo praticável

mas nem mesmo concebível

mais que uma praça verdadeira

é o pesar ou o remorso de uma praça

ou talvez até mesmo (e não para todos

mas só para quem há tempo cultiva

mais pensamentos de morte que de vida)

nada mais que seu nome. ${ }^{16}$ (RABONI, 2006, p. 1251)

O evento trágico é relembrado aqui por meio de seu nome que, em si, é emblemático. O ataque à Banca Nazionale dell'Agricoltura, que teve lugar no dia 12 de dezembro de 1969 , marca de maneira indelével a história de Milão e da nação inteira. Mesmo que em um primeiro momento tenha se suspeitado dos anárquicos, sucessivamente surgiu a matriz fascista do atentado, levando a exponentes de Ordine nuovo. Esse evento marca o início da fase de atentados na

16 "Ogni tanto succede / di attraversare Piazza Fontana. / Come parecchie piazze di Milano / anche Piazza Fontana / con le sue quattro piante stente / e il suo perimetro sfuggente / come se ormai nessuna geometria / fosse non dico praticabile / ma neanche concepibile / più che una piazza vera e propria / è il rimpianto o il rimorso d'una piazza / o forse addirittura (e non per tutti / ma solo per chi da tempo coltiva / più pensieri di morte che di vita) / nient'altro che il suo nome" (tradução de Agnes Ghisi e Elena Santi). 
Itália, os chamados "anos de chumbo", em que o clima de terror permeava, principalmente, as grandes cidades. Além disso, a história processual do crime é bastante complexa e atormentada, terminando em uma substancial impunidade de executores e mandantes.

Nesse texto, o poeta nunca nomeia o que houve na piazza Fontana, nem dá pistas sobre o momento histórico ao qual se refere. A coletânea Barlumi di storia, por sua vez, é muito posterior aos acontecimentos trazidos pelo texto "Por vezes acontece [Ogni tanto oétic]", já que foi publicada apenas em 2002. A última seção das cinco que compõem o livro se dedica, expressamente, a temas ligados à história, com uma vertente expressamente política. O espaço é protagonista, a praça, que deveria ser um lugar de encontro e de troca, e que no poema não é. Algo nesse espaço urbano não é conforme o esperado. Começando pelo primeiro verso, que parece quase eliminar qualquer intencionalidade do percurso que leva à praça. Não é um destino, simplesmente acontece, nas próprias peregrinações, de passar por esse espaço. O poeta caminha na praça e, assim, parece entrar em contato com os ecos da história. A dissonância é projetada na estrutura da praça, cujo perímetro é "fugidio [sfuggente]". Em italiano, é importante pensar na rima com "doídas [stente]", no verso anterior. A aproximação dos dois termos por meio da rima contribui para criar um clima de indeterminação e instabilidade, quase como se o verdadeiro perímetro da praça, sua verdadeira essência, não fosse tão clara, mas desfocada, inapreensível, em sua natureza mais autêntica. Os versos sucessivos mostram outra dupla de termos em rima imperfeita que, como na dupla precedente, emergem com força no texto: "praticável [praticabile]" e "concebível [concepibile]", referidos à geometria da praça, como se o que aconteceu tivesse rompido para sempre sua geometria, que não somente não pode mais ser colocada em prática, mas não pode nem mesmo ser pensada. É um espaço que não existe mais, apagado em sua essência, como se a explosão das bombas na Banca Nazionale dell'Agricoltura tivesse sacudido profundamente as fundações, comprometido desde a base o seu status de praça. Aquilo que o texto de Raboni nos devolve é um espaço ferido, que sofreu uma ação que, de certa maneira, o cancelou, deixando somente "o pesar ou o remorso de uma praça [il rimpianto o il rimorso d'uma piazza]". Ou melhor, talvez o ato violento tenha ido para além disso, apagando tudo e poupando apenas seu nome, já esvaziado, embora tristemente famoso e estonteante.

As atitudes de Raboni e D’Elia, em relação ao fato histórico, são substancialmente diferentes. Por um lado, ambos colocam no centro do próprio gesto poético a história e, diante dela, a poesia não pode se calar, ela é percorrida por uma urgência, é obrigada a dizer: "Enfrentei temas engajados simplesmente porque sentia a urgência, sentia a urgência íntima: ou por um movimento de indignação, ou de preocupação, ou de consternação"17 (RABONI, 2014, s/p). Contudo, D'Elia, apesar de movido pela mesma indignação e desconforto, trabalha de maneira diferente com essa necessidade de falar: assume uma posição política e, com isso, guia o leitor mediante uma interpretação única, eliminando, no caso de Vozes, as sobras possíveis, as ambiguidades no texto e nas referências históricas. Já em Raboni, a história se torna algo que perma-

17 "Io ho affrontato temi civili semplicemente perché ne sentivo l'urgenza, ne sentivo l'urgenza intima: o per un moto di indignazione, o di preoccupazione, o di sgomento". 
nece somente em filigrana, visível só na contraluz, em sua ausência. É um eco que ressoa silenciosamente, um barulho imperceptível, uma tensão que percorre o texto no tênue limiar entre presença e ausência. A referência ao ataque aparece de modo claro somente por meio do nome da praça, lamentavelmente famoso e emblemático. Quem se aproxima do texto pode reviver o trágico episódio a partir da própria vivência e experiência, sem ser guiado, mas percorrendo a praça de maneira livre, no sentido que quiser e puder lhe atribuir. 


\section{Referências:}

BENJAMIN, Walter. Sobre o conceito de história. In: BENJAMIN, Walter. Magia e técnica, arte e política. Ensaios sobre literatura e história da cultura. Obras escolhidas. Vol. I. Tradução de Sergio Paulo Rouanet. São Paulo: Brasiliense, 1994, p. 222-232.

CHELLA, Anna. Raboni, la storia per Barlumi. In: GIRARDI, Antonio et alii. Questo e altro: Giovanni Raboni dieci anni dopo (2004-2014). Macerata: Quodlibet, 2016, p. 345-365.

DIDI-HUBERMAN, Georges. Cascas. Tradução de André Telles. In: Revista Serrote, n.13, mar. 2013, p. 99-133.

DIDI-HUBERMAN, Georges. Diante do tempo. História da arte e anacronismo das imagens. Tradução de Vera Casa Nova e Márcia Arbex. Belo Horizonte: Editora da UFMG, 2015.

LAMPUGNANI NIGRI, Arrigo. Ping-pong in Corso Venezia. In: POGGI, Valeria (org.). L'emozione della poesia. Testi e interventi sull'opera e la figura di Giovanni Raboni. Azzate: Stampa, 2014, p. 17-22.

PETERLE, Patricia; SANTI, Elena. Vozes: cinco décadas de poesia italiana. Rio de Janeiro: Editora Comunità, 2017.

RABONI, Giovanni. L'opera poetica. Milão: Mondadori, 2006.

RABONI, Giovanni. Tutte le poesie 1949-2004. Torino: Einaudi, 2014.

RIVISTA Atelier, n. 29, mar. 2003. Disponível em: http://www.andreatemporelli.com/wp-content/ uploads/2015/08/Atelier-29-VIII-marzo-2003.pdf. Acesso em 24 ago. 2020.

ZANZOTTO, Andrea. Per Giovanni Raboni. In: RABONI, Giovanni. L'opera oética. Milano: Mondadori, 2006, p. XI-XVIII.

Recebido em: 24/08/2020

Aprovado em: 13/10/2020 